
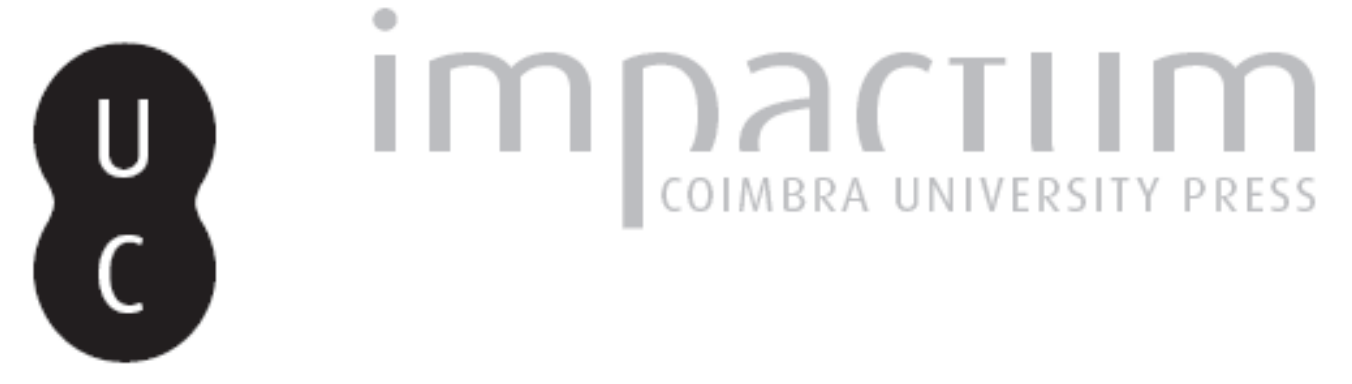

\title{
[Recensão a] M. C. Nogueira Serens - A monopolização da concorrência e a (re- )emergência da tutela da Marca
}

\author{
Autor(es): $\quad$ Calvete, Victor \\ Publicado por: Faculdade de Direito da Universidade de Coimbra \\ URL \\ persistente: \\ URI:http://hdl.handle.net/10316.2/24755 \\ DOI: \\ http://dx.doi.org/10.14195/0870-4260_51_9 \\ Accessed : $\quad$ 26-Apr-2023 15:19:44
}

A navegação consulta e descarregamento dos títulos inseridos nas Bibliotecas Digitais UC Digitalis, UC Pombalina e UC Impactum, pressupõem a aceitação plena e sem reservas dos Termos e Condições de Uso destas Bibliotecas Digitais, disponíveis em https://digitalis.uc.pt/pt-pt/termos.

Conforme exposto nos referidos Termos e Condições de Uso, o descarregamento de títulos de acesso restrito requer uma licença válida de autorização devendo o utilizador aceder ao(s) documento(s) a partir de um endereço de IP da instituição detentora da supramencionada licença.

Ao utilizador é apenas permitido o descarregamento para uso pessoal, pelo que o emprego do(s) título(s) descarregado(s) para outro fim, designadamente comercial, carece de autorização do respetivo autor ou editor da obra.

Na medida em que todas as obras da UC Digitalis se encontram protegidas pelo Código do Direito de Autor e Direitos Conexos e demais legislação aplicável, toda a cópia, parcial ou total, deste documento, nos casos em que é legalmente admitida, deverá conter ou fazer-se acompanhar por este aviso.

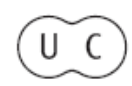




\section{UNIVERSIDADE DE COIMBRA \\ FACULDADE DE DIREITO}

BOLETIII DE CÊACCLS ECONÓNCACAS

VOLUME LI

$\begin{array}{llll}2 & 0 & 0 & 8\end{array}$

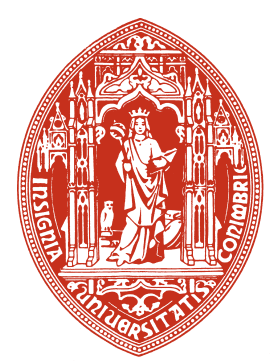

COIMBRA 


\section{Recensões}

\section{C. Nogueira Serens, A Monopolizaçãa da Concorrência $e$ a (Re-)Emergência da Tutela da Marca, Almedina, 2007, 1335 pp.}

Apesar de alguma evidência em contrário, não há razão para que uma tese de doutoramento em Direito tenha de ser como um Manual de Instruções: minuciosa, mas entediante. Certo, o fascínio - como a beleza - "lies in the eyes of the beholder", mas há seguramente uma relação entre a largura de banda do tratamento do tema e o interesse que desperta: especificidades de um dado instituto podem concitar as mais apaixonadas divergências ${ }^{1}$, mas a subtileza da discórdia só mobiliza os iniciados. Já abordando "the big picture" até os mais distraídos da matéria podem ser arrebatados, sobretudo se houver uma narrativa estruturante do sentido dessa visão global, e quer o A. intente revelar a própria racionalidade intrínseca aos factos, ou uma sua reconstrução retroactiva ${ }^{2}$.

${ }^{1}$ Basta pensar (para recorrer a exemplos que - muito justificadamente - não foram objecto de teses de doutoramento) nas consequências da inobservância da forma nos contratos-promessa, na delimitação do thema decidendum no parecer do (ora extinto) Conselho da Concorrência em operações de concentração de empresas, na posologia da dita Lei da Paridade, ou na legalidade da fixação de preços de revenda (Resale Price Maintenance).

${ }^{2}$ Em Direito, tal como há Programas de Investigação Técnicos - se intentam explicar as diversas declinações do funcionamento de um instituto - há Programas de Investigação Filosóficos - se o seu objectivo é esclarecer a causa das coisas ou, alternativamente, o que, num juízo de prognose póstuma, pode ser aceite como uma aproximação a isso. A diferença entre um e outro destes desígnios 
A tese de doutoramento de Manuel Couceiro Nogueira SERENS tem tudo isso: uma visão abrangente no tempo (entre, fundamentalmente, o $3^{\circ}$ quartel do Século XIX e o $2^{\circ}$ quartel do Século XX, mas com demoradas incursões à Antiguidade Clássica $^{3}$ e à Idade Média ${ }^{4}$ ); uma visão abrangente no espaço (centrada na evolução legislativa e jurisprudencial em França ${ }^{5}$, na Alemanha ${ }^{6}$ e nos $\mathrm{EUA}^{7}$, mas com referências, ente outras, à ordem jurídica nacional ${ }^{8}$, inglesa ${ }^{9}$ e comunitária $^{10}$ ); e uma visão abrangente no âmbito (a tutela da marca, à qual consagra a Parte II da

prende-se com o estatuto da reflexão teórica: para quem acredite na homologia dos processos causais e explicativos (e na racionalidade do real), as causas racionais são reais; para quem veja nos processos mentais uma tradução mais ou menos distante da realidade (e aceite a irracionalidade do real), as explicações que fazem todo o sentido podem não corresponder às verdadeiras causas do devir (de que não raro tomam o lugar). Como dizia recentemente ANTÓNIO EMILIANo: "o sentido oculto das cousas é elas não terem sentido oculto nenhum a não ser aquele que thes atribuímos ou que as cousas elas próprias nos suscitam pelo seu inexistente sentido oculto".

Uns e outros programas de investigação podem delimitar-se em extensão (se se espraiam por institutos limítrofes, em busca de contrastes ou semelhanças) ou em profundidade (se a ênfase é na genealogia de um instituto e no seu devir). E em cada um dos quatro campos recortados pelas dicotomias anteriores ainda se pode ser evolutivo - se o que se visa é a re-exposição do state of the art - ou inovador - se as análises ou soluções diferem das estabelecidas.

"A Monopolização da Concorrência e a (Re-)Emergência da Tutela da Marca", é, nesta taxionomia, o resultado de uma linha de investigação Filosófica, simultaneamente em extensão e em profundidade, e inovadora em alto grau.

${ }^{3}$ Nota 80, p. 34; pp. 57-61 e 592-621.

${ }^{4}$ Pp. 62-67, 74-76, 99-114 e 621-683.

${ }^{5}$ Pp. 12-13, 17-24, 34-35, 37-38, 42-50, 79-80, 471-584, 682-683 е 687-796.

${ }^{6}$ Pp. 14-15, 26-27, 38-39, 80-81, 115-309 e 796-884 e nota 2353.

7 Pp. 27-29, 81-83, 311-470 e 885-1143.

${ }^{8}$ Em especial pp. 15-16, 24-25, 32-34, 39, 67-68, 83-92, 101-104 (notas), 108, 422, 1219-1221 e 1231; nota 88 (p. 36), nota 196, nota 257, nota 264 , nota 265 , nota 438 , nota 450 , nota 465 , nota 471 , nota 478 (p. 243 ), nota 846, nota 2140, nota 2287, nota 2327 e nota 2341.

${ }_{9}^{9}$ Pp. 62-66; nota 756 (pp. 364-376), nota 1300 e nota 2353 (p. 1184); e pp. 659-661, 669-670, 885-891, 927-929 e 1091-1103.

${ }_{10}$ Nota 1983 (pp. 981-991), nota 2358 (pp. 1197-1199), nota 2389; pp. $1229-1232$. 


\section{sua dissertação ${ }^{11}$, mas também os regimes da concorrência ${ }^{12}$ e da concorrência desleal ${ }^{13}$, da disciplina societária ${ }^{14}$, da protecção do}

${ }^{11}$ Sob a epígrafe: " $A$ tutela das marcas: uma (outra) forma (ontem como hoje) de evitar a concorrência" (pp. 585-1248). Divide-se em dois capítulos "Sobre a (longa) história das marcas" (pp. 587-683) e "A generalização do uso da marca e da sua (efectiva) tutela no capitalismo industrial: o momento e as razões" (pp. 685-1248).

${ }^{12}$ Pp. 11-29, 99-114, 283-309, 319-470, 475-482, 506-584 e 1136-1137. Passagens-chave: "a diferença entre a disciplina da concorrência no tempo das corporaçoes e aquela que se afirmou no tempo dos sindicatos industriais residia fundamentalmente no seguinte: esta última dirige-se a concorrentes em situação-de-desigualdade-na-concorrência e, por conseguinte, trata de forma igual o que é desigual - os (muito) grandes e os (muito) pequenos empresários, que então passam a (co-)existir no mercado, estão, com efeito, todos sujeitos às mesmas regras de (não-)concorrência -, a primeira daquelas disciplinas, por sua vez, era muito mais équa, pois que entre os seus destinatários (os membros das corporações) não subsistiam diferenças sensiveis no que tange à dimensão empresarial, estando todos eles, por conseguinte, numa situação-de-igualdade-na-concorrência." - p. 114.

"O direito antitrust, que se revelara incapaz de travar a concentração horizontal, de que esses industriais eram filhos, deixou, outrossim, de constituir, graças a essa opção [de não proibição per se de contratos de exclusividade], um obstáculo, já à integração vertical, já às diversas formas de distribuição indirecta-integrada, as quais, assentando em "simples" contratos (de distribuição), eram de muito mais fácil consecução. O falhanço do referido direito assumia assim uma dupla faceta: por um lado, não conseguira impedir a concentração do poder da oferta e, por outro, acabou por permitir que esse poder neutralizasse o poder da procura." - pp. 458-459.

${ }^{13}$ Pp. 764-796, 862-884, 946-964, 1070-1145. Passagens-chave: “recorrendo à disciplina da concorrência desleal (...) conseguiram[-se] repetir, no sistema sócio-económico-político, que se dizia baseado no princípio da liberdade de comércio e indústria (ou, o que vale o mesmo, o princípio da liberdade de iniciativa económica), as soluções mais tipicamente corporativas do Ancién Régime, que sempre foram tidas, por isso mesmo, como profundamente anti-concorrenciais." - p. 789.

"Em aplicação deste preceito [S 1 da UWG, promulgada em 1909] - num processo análogo ao que ocorreu em França, ainda na segunda metade do século XIX, com base no art. 1382 Code civil * inseriu-se o direito das marcas (e também, diga-se, o direito dos restantes sinais distintivos típicos) na disciplina da concorrência desleal, fazendo-se daquele(s) uma parte desta, com o claro propósito de deixar de permitir muito daquilo que não podia ser proibido no quadro daquele(s) primeiro(s) normativo(s) - numa forma mais directa de dizer: com o claro propósito de alargar os "espaços monopolísticos"." (^ Nota suprimida). - p. 862.

"Comprovado como está que, também na ordem jurídica norte-americana, a generalização do uso e da consequente tutela da marca ocorreu na época da monopolização da concorrência, e sabendo nós que essa tutela, assumindo feição particular, era necessariamente 
consumidor $^{15}$ e da legislação social ${ }^{16}$, consideradas na Parte $\mathrm{I}^{17}$ como
instâncias de revelação de duas tendências evolutivas mutuamente

incompleta e, nessa medida, não poderia deixar de ser acompanhada da instituição de uma certa disciplina da concorrência - que nos EUA, "perhaps from the French Concurrence Déloyale"*, acabou por tornar o nome de "unfair competition"* -, cuja ratio era precisamente suprir essa incompletude (monopolística), poderíamos sem mais concluir que tal disciplina está, também ela, ligada à monopolização da concorrência, no sentido de que foi esta que engendrou aquela." ( $\star$ Notas suprimidas). - p. 1072.

${ }^{14}$ Pp. 30-50, 86-89, 130-250, 352-356, 477-505. Passagem-chave: "na sociedade anónima, (...) a dimensão da empresa, que é a medida do poder daqueles que a administram, não interfere com a responsabilidade dos sócios, que é sempre limitada ao valor da respectiva entrada. Dado que um grande poder (de mercado), centrado numa grande empresa de que a sociedade anónima fosse titular, não fazia aumentar a responsabilidade dos seus sócios (pelas dívidas sociais, entenda-se), natural seria que estes não receassem a dimensão da empresa. Vale isto por dizer que neste tipo de sociedade, e ao contrário do que vimos acontecer nas sociedades em nome colectivo e em comandita, a ambição de poder (de mercado) dos sócios (de todos ou de alguns deles) não era auto-controlada. (...)

Essa perigosidade político-económica das sociedades anónimas tinha, aliás, múltiplas facetas. A especulação (e mesmo a agiotagem) inerente à negociabilidade das acções (...) seria uma delas. Outra seria, (...) o monopólio, exactamente por causa do ilimitado potencial de crescimento da sociedade anónima." - p. 37.

${ }^{15}$ Pp. 524-534. Passagem-chave: "defesa de uma dada categoria de sujeitos os consumidores - que, concebendo-se como colectividade, não raro vêem os seus interesses tomados como interesses da colectividade mesma (interesse geral, também agora). Partindo-se de uma relação de conflito entre a categoria dos empresários (sujeitos activos de quaisquer formas de reclamo) e a categoria dos consumidores (destinatários; sujeitos passivos), a respectiva decisão-solução não se assume como corporativa, antes se pretende anti-corporativa, buscando desse jeito, justificação (económico-democrática)." - p. 527.

${ }^{16}$ Pp. 1148-1153. Passagem-chave: "não obstante o seu poder de mercado, os sindicatos só podiam funcionar eficazmente se os outsiders não dispusessem de condições para privilegiar a concorrência de preço. Para isso, seria mister eliminar ou, quando menos, atenuar as vantagens-na-concorrência desses mesmos outsiders, e que thes advinham dessa sua situação*. Dizendo de outra maneira, seria necessário uniformizar (ou estandardizar) as condições-de-concorrência. Se os membros do sindicato (como era de regra) se obrigavam a não exceder um certo volume de produção, para assim obstar à descida do preço, impunha-se que as empresas não sindicalizadas não tivessem liberdade de produzir quanto desejassem, e que thes seria tecnicamente possível. É precisamente nesse sentido que aponta, desde logo, a legislação que introduziu limitações ao trabalho de mulheres e de menores e que impunha uma duração máxima à jornada de trabalho e a obrigatoriedade dos descansos semanais. Uma legislação de alcance social iniludivel, sem dúvida; mas o seu efeito (anti-)concorrencial era também inquestionável." ( $\star$ Nota suprimida). - pp. 1148-1149.

${ }^{17}$ Epigrafada "A liberdade de concorrência no século XIX e nos começos do século $X X(O$ exemplo de três países - ainda hoje - mais industrializados)" (pp. 7-584). 
reforçantes: a da desigualização na concorrência e a da limitação na concorrência), tudo convergindo na tese central da sua obra: a de que "a tutela da marca é indissociável da monopolização da concorrência, constituindo, a um tempo, efeito e causa desta." 18

Que esta síntese tem potencial explicativo no cerne da investigação - as marcas - decorre da minuciosa argumentação do A., conduzida naquelas três frentes principais (França, Alemanha, EUA), apresentadas como diferentes (e independentes) concretizações históricas dessa desocultada relação fundamental. Mas o que é ainda mais impressivo na tese do A. é o efeito de contágio dessa mesma hipótese, desde logo na explicação da evolução da tutela da concorrência desleal:

18 Pp. 936-937. O A. revela os propósitos monopolísticos de diversos passos do seu regime: "açambarcamento de marcas (depósito de marcas defensivas) e de alargamento do âmbito merceológico da respectiva tutela (depósito da marca, cuja propriedade fora adquirida com base no seu uso para contradistinguir determinados produtos - produtos defensivos, como atrás the chamámos -, para produtos diferentes, passando, por conseguinte, essa propriedade, que se dizia "relativa", a ser tendencialmente "absoluta"...)" (p. 731), "total assimilação do depósito da marca ao uso desta" (p. 734) - pp. 729-734; e extensão do controlo da utilização das marcas: na publicidade - pp. 741-743 -, em casos de troca do pedido ("usurpação oral expressa" ou "tácita") - pp. 743-745 -, de aposição fraudulenta da marca - pp. 745-756 e de supressão da marca - pp. 756-762. E, como escreve a pp. 921-922: "Aligeirada, sobremaneira, a prova do secondary meaning; introduzida a teoria do secondary meaning in the making; desnaturado o pressuposto da "intenção fraudulenta" - para a consecução do objectivo tido em vista, que era, recorde-se, o reforço da protecção das "non-technical trademarks" - equiparando-a à das "technical trademarks" -, houve ainda que promover a aproximação da "action for passing off or unfair competition" à "action ot trademark infringment "em dois outros pontos. Em primeiro lugar, o êxito daquela primeira ação, que antes estava dependente da prova da "actual deception" dos consumidores, passou a depender (do convencimento dos juízes a respeito) da "probabilidade" (likelihood)* de os consumidores se enganarem; (...)

O segundo ponto (...) respeitou ao conteúdo da injunction, a proferir no quadro daquela primeira ação (...) deixando os tribunais de se sentirem impedidos de, em resultado de uma "action for passing off or unfair competition", decretar uma absolute injunction*, à semelhança do que acontecia no quadro de uma "action of trademark infringement"." ( $\star$ Notas suprimidas). Com a consequência desvendada a seguir (p. 925): "Para além de permitir uma tutela adequada(mente monopolística) das "non-technical trademarks", dissimulava a sua proprietarização, furtando-se, pois, à crítica de conduzir à constituição de monopólios sobre os "signos descritivos"." 
Essa relação (conexão) da tutela da marca e da disciplina da concorrência desleal com a monopolização da concorrência - a consumação desta (por via de "sindicatos industriais", e não só) tornou inevitável a afirmação daquelas, estabelecendo-se, em seguida, uma espécie de espiral monopolística: quanto mais a concorrência se monopolizou tanto mais necessário se tornou reforçar a tutela da marca e a luta contra a concorrência desleal (alargamento do âmbito da respectiva disciplina), sendo que, por uma e outra via se estava, afinal, a incrementar o próprio processo de monopolização da concorrência, ajudando, outrossim, à sua irreversibilidade ${ }^{19}$.

No fundo, o que o A. assim enuncia é o alastrar a esse outro instituto (a concorrência desleal ${ }^{20}$ ) do seu paradigma explicativo

${ }^{19}$ P. 1070. Na p. 1145 o A. inclui um diagrama que ilustra essas relações mútuas:

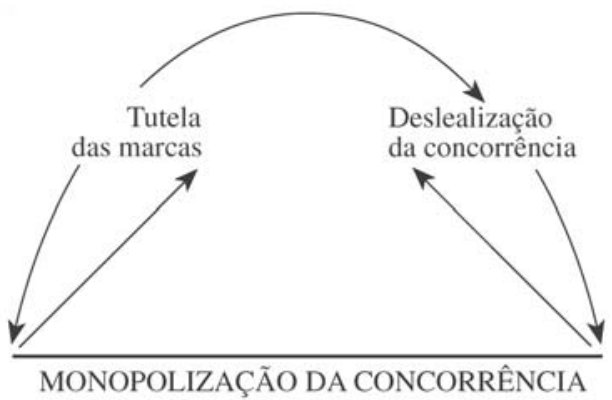

${ }^{20}$ Passagens-chave: "o âmbito da disciplina da concorrência desleal alarga[-se] quando se reduz o âmbito da defesa da liberdade de concorrência." - p. 398. (EUA).

"Cumpria-se dessa maneira a última fase de um processo, detectável, aliás, noutras áreas da chamada "disciplina da concorrência": primeiro, invocando a liberdade contratual, os empresários restringem a livre concorrência, banindo certas das suas formas; depois, dadas as manifestas insuficiências desse "instrumento", aí temos o recurso à deslealização dessas mesmas formas de concorrência: sobre os outsiders, que não desistam delas, pairará então a infâmia - e é tanto mais assim quanto mais eticizante for o entendimento da disciplina da concorrência desleal -, que tornará mais eficaz a proibição, é certo, mas sem eliminar a alea que a mediação construtiva dos tribunais sempre acarreta; mais segura, pela sua maior densificação* - e esta é, pois, a última fase do aludido processo - será a proibição dessas formas de concorrência por via da lei, verdadeira regra de conduta que se impõe a todos os empresários, e não modo de comportamento desejado (e, por isso, proposto) por (alguns d)eles ${ }^{\star} . "$ ( Notas suprimidas). p. 525. (França). 
da re-emergência histórica das marcas ${ }^{21}$, tal como o poderia ter feito, em termos semelhantes, em relação às alterações ao figurino e regime das sociedades ${ }^{22}$, e às condições da sua fusão ${ }^{23}$, aos

"O préstimo monopolístico da disciplina da concorrência desleal resulta assim evidente: permitia alargar os espaços de não-liberdade (ou, se preferirmos, de exclusivismo) para lá das fronteiras que o legislador traçara de forma assaz generosa, como atrás vimos) aos monopólios que as marcas constituíam." - p. 771.

"Os efeitos dessa crescente importância (quantitativa e qualitativa) da cláusula geral da UWG de 1909, que vigorou por quase cem anos (...) resultam óbvios: as condutas concorrenciais, que se diziam contrárias aos bons costumes, tornaram-se cada vez mais numerosas, sendo certo que esse crescente rigor na repressão da concorrência desleal, que se diz inspirado pela preocupação com a defesa da liberdade de concorrência (!), foi acompanhado de uma (igualmente) crescente permissividade face aos cartéis*, eles sim, inequivocamente inspirados pela preocupação de restringir a liberdade de concorrência." ( $\star$ Nota suprimida).- pp. 872-873. (Alemanha).

${ }^{21}$ Passagens-chave: "a sua raiz [da "concorrência desleal" (e da "concorrência ilícita") na ordem jurídica francesa] é, afinal, a mesma da tutela da marca: a monopolização da concorrência." - p. 774.

"a generalização do uso da marca e, consequentemente, a generalização da sua tutela, decorre(ra)m da monopolização da concorrência; (..) o mesmo acontece(u) relativamente à disciplina da concorrência desleal. (...) ambas as disciplinas, ou seja, a disciplina da marca e da concorrência desleal, que começa(ra)m por ser efeitos da monopolização da concorrência, logo se torna(va)m causas desta." - p. 1144.

${ }^{22}$ Passagens-chave: [o "sistema de concessão"] "funcionava como um instrumento de política económica, posto ao serviço da liberdade de concorrência, com não pouca similitude - diga-se - com as chamadas leis de defesa da concorrência dos nossos dias, na parte, é claro, em que estas (rectius: os "manuseamentos" que elas permitem) cuidam de impedir um excessiva concentração ao poder de mercado." - p. 130. A sua substituição pelo " "sistema normativo" (...) comummente apresentada como eminentemente liberal (...) foi tão "liberal" quanto o seria hoje a abolição das leis de defesa da concorrência..." - p. 131.

"a possibilidade de uma sociedade anónima participar (como simples investidor que seja) no capital de outras sociedades do mesmo tipo, para além de potenciar o aparecimento de empresas de maior dimensão do que aquelas que seriam constituídas se a sociedade anónima apenas pudesse recorrer ao capital de pessoas humanas, coloca alguns (poucos) accionistas em condições de se assenhorearem da vontade da sociedade e, consequentemente, de dizerem qual o interesse social." - p. 135.

"ao contrário do comummente propalado, afigura-se-nos que, na base da criação desse novo tipo societário, não esteve a preocupação com a necessidade de dar alento à concorrência, estimulando o aparecimento de novos concorrentes de pequena/média dimensão - os novos concorrentes que seriam as GmbH para cuja constituição bastava a vontade de um número reduzido de pessoas (duas já seriam suficientes), que não teriam de reunir 
avultadas somas de capital, e às quais se concedia o benefício da limitação da responsabilidade -, mas antes a preocupação com a necessidade de robustecer a não-concorrência, colocando ao dispor dos cartéis uma forma de organização que aumentasse a sua eficácia monopolística." - p. 150.

"A especificidade do regime da pena convencional, que constava do \$348 HGB, pode bem ser entendida como uma prova da solicitude do legislador em relação a essa prática [de "estatuição de penas convencionais, no quadro dos acordos de cartel"], que contribuía, obviamente, para reforçar a eficácia monopolística dos cartéis. Nesse preceito, que assim se afastava da doutrina do $\ 343 B G B(.$.$) , era expressamente afirmado que$ as penas convencionais prometidas pelos comerciantes no exercício do seu comércio, por mais desproporcionadamente elevadas que se revelassem, não eram passíveis de redução" - nota 488, p. 251. (Alemanha).

"se os trusts se transformaram, $e$, transformando-se, tornaram irreversivel o referido processo [de concentração], foi porque o legislador (em vários Estados da União*) criou condições para essa transformação. (...) se os trusts se transformaram (rectius: se se puderam transformar) em grandes sociedades anónimas foi porque, tendo-se facilitado as chamadas "reorganizations" um limite máximo*, se admitiram entradas em bens diferentes de dinheiro* (serviços incluídos ${ }^{\star}$ ), se atribuiu competência aos directores para onerar bens imóveis pertencentes ao património social, sem prévia deliberação dos sócios, e se deixou de responsabilizar esses mesmos directores pelas dívidas de montante superior ao capital social*; foi por tudo isto, e também porque essas sociedades, que, nos começos do século XIX, só podiam durar por tempo determinado, passaram no final desse século (na época da transformação dos trusts, pois) a poder durar por tempo indeterminado ${ }^{\star}$, admitindo-se, do mesmo passo, a sua livre constituição para "any lawful purpose", e não apenas, como começara por acontecer, para o exercício em comum de certas indústrias, que eram taxativamente enumeradas ${ }^{\star}$. Por outro lado, se os trusts se transformaram em "grupos de sociedades", encabeçados por uma holding, foi porque o legislador (no caso, o legislador de vários Estados da União) o quis. Com efeito, (...) em vários Estados norte-americanos, as primeiras leis sobre a sociedade anónima proibiam expressamente a sua participação no capital de outras sociedades do mesmo tipo; noutros Estados, sendo as respectivas leis omissas sobre esse ponto, os tribunais concluíam pela ilegalidade dessa participação, socorrendo-se, (...) da teoria ultra vires. (...) As coisas só passaram a ser diferentes, (...) precisamente por causa da intervenção do legislador - num primeiro momento, do legislador do Estado de New Jersey, rapidamente imitado pelos legisladores de muitos outros Estados da União -, admitindo expressamente a participação de sociedades anónimas no capital de outras sociedades do mesmo tipo (introdução da chamada "holding-company-dause”). ( Notas suprimidas). - pp. 353-356. (EUA).

"as sociedades em nome colectivo não mais foram utilizadas para a organização jurídica dos sindicatos industriais (e dos seus "comptoirs de vente") quando passou a ser possível organizá-los livremente sob a forma de sociedade anónima. O primeiro passo nesse sentido foi dado com a Lei de 23 de Maio de 1863, que subtrain ao regime de 
auto-rização a constituição de sociedades anónimas de capital não superior a 20 milhões de francos (as chamadas "sociétés à responsabilité limitée"). Seguiu-se-lhe, (...) a Lei de 24 de Julho de 1867, cujo artigo 21, Sl, dispunha que, "à l'avenir, les sociétés anonymes pourront se former sans autorisation du gouvernement"; assim se revogava o artigo 37 do Code de commerce, admitindo-se, por conseguinte, a livre constituição de sociedades desse tipo, independentemente do montante do seu capital. Claro está que esta "liberalização" da sociedade anónima - as aspas pretendem significar que o favor à sociedade anónima, que adveio da consagração do "sistema normativo", sendo um favor à grande empresa, foi, à luz do ideal de concorrência, profundamente anti-liberal - não teve apenas efeitos monopolistas por ter propiciado uma melhor forma de organização aos sindicatos industriais (de grau superior). Teve-os também (e sobretudo) porque viabilizou o processo de concentração económico-empresarial, com a consequente desigualização-dos-concorrentes-na-concorrência." - pp. 493-494.

"Nunca tendo questionado a possibilidade de uma sociedade anónima (ou de outro tipo) ser sócia de outras sociedades do mesmo tipo (ou de tipo diferente), a doutrina francesa aceitava, sem reservas, a sociedade omnium. Discutida, nesse contexto, era apenas a questão de saber se essa sociedade, em vez de adquirir as aç̧ões, na sua integralidade, digamos assim, podia adquirir apenas o direito do voto. (...) Responder afirmativamente significava facilitar (ainda mais) o processo de concentração empresarial; com efeito, era muito menos dispendioso (...) dotar a sociedade omnium do capital necessário para adquirir a maioria dos votos conferidos pelas ações de várias sociedades (directa ou indirectamente) concorrentes do que dotá-la do capital necessário para adquirir a maioria das acções dessas mesmas sociedades." - p. 504. (França).

${ }^{23}$ Passagens-chave: "A evolução do regime legal da fusão e a própria orientação jurisprudencial (...) apontavam num sentido bem definido: facilitar as operações de concentração económica, realizadas por essa via. Servindo os interesses de alguns concorrentes, é dizer, de alguns empresários - concretamente, dos empresários de maior dimensão (...) -, essa opção (legislativa e jurisprudencial) não aproveitava (é o mínimo que se pode dizer) à liberdade de concorrência, exactamente porque fomentava a desigualdade entre os concorrentes." - p. 129 (Alemanha).

"No que respeita à fusão, o aligeiramento dos pressupostos da sua legalidade manifesta-se das mais diversas formas, (...) Não deixaremos, (...) de referir a regra - que foi sendo acolhida pelas leis sobre a sociedade anónima de vários Estados da União, ao longo do século XIX -, segundo a qual a fusão, embora sujeita à aprovação da assembleia geral da(s) sociedade(s) absorvenda(s) ou das sociedades fundidas, podia ser deliberada pela maioria (em regra, de $2 / 3$ dos votos;(...)) Igualmente relevante foi a evolução do regime da "sale of assets". Em aplicação das regras da common law, os tribunais norte-americanos começaram por fazer depender a validade dessa operação do consentimento unânime dos accionistas da sociedade alienante. Esta exigência ou, numa outra perspectiva, esta dificuldade acabou por ser arredada, na linha, aliás, do que se verificon em relação às outras duas modalidades de "reorganization": "By statutory provision adopted in more than forty states a prosperous and going corporation may with the vote 
or consent of its board of directors and two-thirds of its voting shareholders or some other specified majority, sell and convey all or substantially all its property rights" (Ballantine on Corporations, (...)). Este aligeiramento do quorum deliberativo foi acompanhado de uma outra medida de grande alcance: a possibilidade de ser a própria sociedade adquirente "a criar a moeda" com a qual "pagaria" os activos da sociedade alienante. Com efeito, e voltando a usar palavras de Ballantine on Corporations, 671, "in more than half of the states statutes have been adopted which authorize a corporation to sell its assets in exchange for the shares and of the purchasing corporation". É claro que, fazendo-se uso desta faculdade, já não estaria em causa uma venda - e por isso escrevemos pagaria entre aspas -, mas uma troca (de activos ou de estabelecimento) ou mesmo uma atribuição a sociedade". - nota 724, pp. 353-354. (EUA)

"a doutrina e a jurisprudência francesas aligeiravam o processo de fusão de sociedades - maxime das sociedades anónimas e das sociedades em comandita por acções, pois que, como já então se reconhecia*, a fusão de sociedades destes dois tipos é muito mais frequente do que a das "sociedades de pessoas" -, que passa a ser encarado como o resultado lógico da evolução económica no sentido da concentração de capitais*. Inadvertidamente, em 1893, o legislador contrariou essa tendência "liberalizadora" (...): a realização das entradas em espécie deixou de poder ser diferida e, a mais disso, as acções representativas dessas entradas ("actions d'apport") não podiam ser "détachées de la souche" e não eram "négociables que deux ans après la constitution définitive de la société" (...) Solícito, o legislador não tardou a "emendar a mão". Em 1902, e por força do art. 2 da Lei de 9 Julho (sobre as chamadas 'aç̧ões de prioridade ou privilegiadas” ) (...) [o] princípio da não-negociabilidade era (...) arredado em relação às "actions d'apport" emitidas pela sociedade absorvente ("fusão-absorção") ou pela nova sociedade ("fusão-constituição") desde que a(s) sociedade(s) absorvida(s), no primeiro caso, ou as sociedades fundidas, no segundo caso, tivessem sido constituidas há mais de dois anos. Este regime só era, porém, aplicável às fusões de sociedades anónimas, que eram as únicas ("par un oubli singulier" do legislador diziam E. Thaller $/ P$. Pic $c^{\star}$ ) expressamente referidas no parágrafo que fora aditado ao art. 3 da Lei de 24 de Julho de 1867. De fora ficavam, pois, os casos de fusão envolvendo sociedades em comandita por aç̧ões. Sendo grave, na perspectiva, é claro, da propensão monopolista (também) então reinante, essa não era a única "lacuna" do aludido preceito: o seu regime só valia para o futuro, ou seja, para as fusões de sociedades anónimas constituídas depois de 1902, o que - e para dizer de novo com E. Thaller/P. Pic"rendait ses prescriptions illusoires pour nombre d'entreprises" $*$. Entre as muitas empresas (rectius: sociedades), para as quais as prescrições do novo parágrafo do art. 3 da Lei de 24 de Julho de 1867 eram ilusórias, contavam-se, evidentemente, aquelas que participavam nos "sindicatos de grau superior" então existentes; e eram precisamente essas sociedades, dado o processo de transformação em grandes empresas (organizadas sob a forma de sociedade anónima) por que passavam alguns desses sindicatos, que mais reclamavam a remoção do obstáculo posto à fusão pelo $\ 2$ do art. 3 da referida lei (na sua versão de 1893). Solícito, uma vez mais, o legislador rapidamente interveio. Em 16 de Novembro de 1903, foi publicada uma nova lei, cujo art. 2 deu nova redaç̧ão ao art 3, 
contratos colectivos de trabalho ${ }^{24}$, às cedências (definitivas ${ }^{25}$ ou temporárias ${ }^{26}$ ) de estabelecimentos comerciais, à publicidade

S 3, da Lei de 24 de Julho de 1867, que então passou a dispor o seguinte: "En cas de fusion de sociétés par voie d'absorption ou de création d'une société nouvelle, englobant une ou plusieurs sociétés préexistantes, l'interdiction de détacher les actions de la souche et de les négocier ne s'applique pas aux actions d'apport attribuées à une société par actions [anónima ou em comandita], ayant, lors de la fusion, plus de deux ans d'existence"; "la presente loi - acrescentava ainda o preceito modificante - est applicable aux sociétés fondées antérieurement ou postérieurement à la presente loi”. ( ${ }^{\star}$ Notas suprimidas). - pp. 498-500. (França).

${ }^{24} \mathrm{Pp}$. 1153-1157. Passagens-chave: "Nas últimas décadas do século XIX, paralelamente à aplicação da "legislação social" e, em muitos casos comple(men)tando-a, as grandes empresas, protagonistas dos sindicatos industriais, socorreram-se de um outro meio para expelir do mercado os outsiders económico-financeiramente menos apetrechados ou, quando menos, para dificultar a sua aç̧ão, obstaculizando, do mesmo passo, a entrada de newcomers ou, como também poderíamos dizer, mantendo em respeito a concorrência potencial. Referimo-nos aos "contratos colectivos de trabalho"." - p. 1153.

"As "conventions collectives" e os "Tarifvertrage" (...) eram, em regra, celebrados entre empresários que integravam os sindicatos industriais e os sindicatos operários do mesmo sector; esses empresários (insiders) obrigavam-se a observar determinadas condições de trabalho, que eram fixadas, e que respeitavam a aspectos tão diversos como o montante (mínimo) dos salários - que, por vezes, era indexado ao preço a que o sindicato industrial vendesse os respectivos produtos (as chamadas "escalas móveis" ou, como diziam os autores alemães da época, as "gleitende Lohnskale") -, os horários de trabalho e os repousos semanais, a higiene e segurança nos locais de trabalho, o prazo pré-aviso de despedimento, etc. ${ }^{\star}$. Entre as obrigações assumidas pelos trabalhadores, enquanto membros dos sindicatos (operários), signatários dos contratos respectivos, destacava-se a de trabalharem exclusivamente por conta dos empresários (insiders ou outsiders) que oferecessem "condições de trabalho" iguais (ou, eventualmente, superiores) às fixadas nos respectivos contratos - no que respeitava aos salários, a obrigação de exclusividade era recíproca, pois que os empresários (insiders) se vinculavam a não empregar trabalhadores que aceitassem um salário inferior. Se os trabalhadores cumprissem essa sua obrigação (de boicote), muitos seriam os empresários de menor dimensão (outsiders) cujo expelimento do mercado seria inevitável, como muitos seriam os empresários potenciais que não passariam desse estádio, é dizer, que não entravam no mercado exactamente porque não dispunham de capacidade económico-financeira que lhes permitisse suportar os custos das novas "condições de trabalho"; por outro lado, os empresários (outsiders ou newcomers), económico-financeiramente mais bem apetrechados, e que, por isso mesmo, não obstante esse aumento de custos, se mantinham ou acediam ao mercado, perdiam competitividade, deixando obviamente de poder privilegiar a concorrência de preço para contestar as posições adquiridas pelas empresas de maior dimensão, protagonistas dos sindicatos industriais; por outro lado ainda, cumprindo todos os empresários signatários do contrato colectivo (os insiders, pois) as "condições de trabalho" a que se vinculavam, se é verdade que todos eles passavam a dispor das mesmas condições-de-concorrência, é 
enganosa $^{27}$ e, de um modo geral, à protecção dos consumidores ${ }^{28}$, às obrigações de não concorrência ${ }^{29}$ e à própria legislação de

também inquestionável que essa igualização, ou melhor, estandardização, não thes aproveitava em igual medida, pela razão simples, mas decisiva, de que encargos ou custos idênticos se reflectem de maneira muito diferente em empresas com diferente dimensão, o que vale por dizer que os principais beneficiários dos contratos colectivos de trabalho (encarando-se estes pelo lado dos empregadores) eram os empresários de maior dimensão que os outorgavam." - pp 1154-1155.

${ }^{25}$ Pp. 1159-1167. Passagem-chave: "sob a capa dos negócios sobre a empresa, que a concepção desta como bem no tráfico (...) tornara passíveis, estavam negócios cujo objecto era a própria (liberdade) de concorrência, que assim eram legalizados. (...) Ou seja, nos seus resultados, as compras de empresas com a finalidade de as liquidar reconduziam-se, afinal, a compras de concorrência, que constituíam, digamos, a causa dos acordos de liquidação (ou, se preferirmos, dos "acordos de encerramento") (...)" - p. 1167.

${ }^{26} \mathrm{Pp} .1167-1171$. Passagem-chave: "mesmo no silêncio do respectivo contrato, e por todo o tempo de vigência deste, o locador/(con)cedente da empresa deixava de poder concorrer, ou seja, ficava impedido de intervir no mercado que era o da empresa locadal (con)cedida (...) Findo o contrato, e admitindo que as partes (...) nada estipulavam a esse respeito, pareceria lógico que o ex-locatário/(con)cessionário ficasse impedido de concorrer com o ex-locador/(con)cedente. As razões que costumavam ser apontadas para justificar a obrigação implícita de não concorrência do transmitente (a título definitivo e por acto entre vivos) da empresa valiam, em larguíssima medida, nessa outra situação. A verdade, porém, é que esse entendimento nunca se conseguiu impor. Preocupação com a defesa da liberdade de concorrência - dizem muitos. Nada disso. Revertendo ao caso da locação/ (con)cessão de exploração de empresas envolvendo os membros dos sindicatos industriais ou os próprios sindicatos industriais, na qualidade de locatários/(con)cessionários, encontramos aí a verdadeira ratio da solução: uns e outros não podiam, como ex-locatários/(con)cessionários, e pela natureza das coisas, ficar impedidos de continuar a explorar as suas empresas ou, o que vale aqui o mesmo, de voltar a concorrer com os ex-locadores/ (con)cedentes." - pp. 1170-1171.

${ }^{27}$ Passagem-chave: "ganha ainda mais força a ideia, que sempre foi a nossa*, de que, através da proibição da publicidade enganosa, a tutela dos interesses dos consumidores não é senão reflexo da necessidade de defender o interesse típico (da categoria) dos empresários - trata-se, pois, de uma disciplina de carácter corporativo." - p. 867. ( Nota suprimida, remetendo para uma anterior obra do A.: A proibição da publicidade enganosa: Defesa dos consumidores ou proteç̧ão dos concorrentes?, separata do Boletim de Ciências Económicas, vol. XXXVII, Coimbra, 1994).

${ }_{28}$ Passagens-chave: "Por nossa banda sempre pensámos que essa espécie de "panaceia universal", que é a (preocupação com a) defesa do consumidor, só vai até onde o permitir (a necessidade de salvaguardar) os interesses empresariais típicos (corporativos, hoc sensu)." - nota 1090, p. 527.

"muitas das opções político-jurídicas, nas quais se insinua a defesa dos interesses dos consumidores, não visam senão resolver conflitos intra-empresariais (e, por conseguinte, 
protecção dos trabalhadores ${ }^{30}$ (tudo temas profusamente tratados em excursos e, ou, notas). Ou seja, subindo mais um degrau de abstracção: a funcionalização de tais institutos ao mesmo propósito rectius: à mesma racionalidade - de transformação das estruturas capitalistas no sentido de domesticar, restringir, disciplinar e diluir a concorrência, em benefício dos detentores do poder de mercado. Movimento esse que se desenrola em paralelo, se bem que não adoptando soluções inteiramente semelhantes, nas três ordens jurídicas

intra-categoria) -, e resolvê-los de harmonia com os interesses profissionais dominantes, que são havidos como os mais conformes à prossecução dos objectivos do sistema económico, e cuja valoração é feita primacialmente em termos de eficientismo." - p. 530.

${ }^{29}$ Notas 496 (pp. 254-282), 756 (pp. 364-386) e 1125 (pp. 544-572), respectivamente, para a situação na Alemanha, Estados Unidos e França, e pp. 1160-1171. Passagem-chave: "A compra das respectivas empresas (ou estabelecimentos) era uma dessas práticas [monopolísticas]. Umas vezes, os compradores eram os membros (mais poderosos, em termos económico-financeiros) dos diferentes sindicatos industriais; outras vezes, que eram as mais, os sindicatos encarregavam-se, eles mesmos, da compra das empresas dos outsiders, usando fundos constituídos para esse efeito. (...) O meio era eficaz, sem dúvida; mas ficava caro. E ficaria ainda mais caro se os vendedores mantivessem intocada a sua liberdade de concorrentes potenciais, ou seja, se thes fosse sempre lícito tornar ao mercado, no momento que thes aprouvesse, e para o exercício da empresa que tivessem por mais conveniente, incluindo, pois, o exercício de uma empresa com o mesmo objecto ou objecto similar ao daquela que antes fora sua; começando por encarecer a prática monopolística, que era a eliminação da capacidade produtiva através da compra das empresa dos outsiders, a admissibilidade dessa espécie de eterno retorno, que poderia, note-se, ser por estes aproveitada para "o mero jogo especulativo"^ (...) acabaria, em última instância, por inviabilizar essa mesma prática.

Com a afirmação da licitude das obrigações de não-concorrência feitas impender sobre os outsiders que vendiam as suas empresas, obstou-se à possibilidade desse "eterno retorno" e, nessa medida, a eficácia da prática monopolística em causa pôde ser salvaguardada." - pp. 1159-1160). [^ Nota suprimida].

${ }^{30}$ Pp. 1149-1153. Passagem-chave: "A generalização da "legislação social" no último quartel do século XIX`e, mais importante do que isso, o êxito da sua aplicação nesta mesma época (...) não podem, pois, ser imputados a uma "mudança de alma" do mundo empresarial: "desumano" nos primeiros tempos do capitalismo industrial, "beneficiente", a partir do início da Grande Depressão^. Essa legislação, que estandardizava as condições-de-concorrência (...), respondeu às necessidades das grandes empresas, que dominavam os sindicatos industriais; debatendo-se com a insuficiência do consumo, a essas grandes empresas não bastava que os seus grandes concorrentes, por acto de vontade, se dispusessem a disciplinar a concorrência (e, disciplinando-a, a controlar a produção), o que faziam coligando-se - necessário era ainda que os concorrentes não coligados não pudessem concorrer na forma que thes aprouvesse." - pp. 1152-1153 ( N Notas suprimidas). 
investigadas - e que, portanto, não pode ser feito relevar das suas características específicas, nem do acaso, mas tem de ser antes imputado a uma ordem de necessidade $e^{31}$.

Uma noção que o A. introduz como alavanca argumentativa comum, e que se tinha perdido de vista em anteriores reflexões sobre esses diferentes temas, é a da "desigualdade-na-concorrência" 32 .

${ }^{31}$ Neste particular não se pode colher uma pronúncia expressa do A., mas, revelada a homologia evolutiva de institutos diversos em diferentes ordenamentos jurídicos, a "sobre-determinante" desse devir comum só podia derivar de: a) circunstanciais razões políticas - uma explicação menos satisfatória atenta a similitude de resultados e a proximidade temporal na sua obtenção; $b$ ) interesses particulares - idem; c) razões estruturais, ligadas sobretudo ao desenvolvimento económico.

A resposta dada pelo A. (no último ponto da sua dissertação) a uma questão conexa, mais limitada - a do "porquê da deslealização da concorrência e da generalização do uso e consequente tutela das marcas quando ocorre(u) a monopolização da concorrência" (p. 1145) - permite imputar-lhe uma concepção estruturalista: tal deslealização ficou a dever-se a uma mutação do mercado (à mesma mutação para a qual foram instrumentais essas alterações na ordem jurídica): enquanto "nessa época (do primeiro capitalismo industrial), o comércio era o elemento organizador do processo de troca e que, por isso mesmo, assumia a tarefa de (procurar) equilibrar a procura com a oferta. (...)

Com a "sindicalização da indústria" ou, como também poderíamos dizer, com a oligopolização, os comerciantes viram fugir-lhes essa posição de supremacia no processo económico, e transformaram-se (rectius: foram transformados) em distribuidores (...)

Essa subordinação da procura dos comerciantes à oferta dos industriais, que reforçava a posição dos consumidores finais, para ser plenamente eficaz, exigia que a oferta dos comerciantes fosse subordinada à procura desses consumidores. Mas, para lograr este objectivo, que era só um meio para alcançar o fim da subordinação da procura dos comerciantes à oferta dos industriais, esta última tinha que ser identificável ou, se preferirmos, tinha que ser retirada do anonimato." - p. 1177.

As marcas (re-)emergem, portanto, para cumprir um desiderato económico, e por causa desse desiderato: o de assegurar " $A$ 'soberania' do consumidor como efeito do domínio dos (sindicatos) industriais sobre os comerciantes" (como reza a epígrafe do último ponto do livro).

${ }^{32}$ Se bem lemos o A., é à a ordem jurídica que se devem pedir contas da rápida obsolescência, a partir do último quartel do Século XVIII, do modelo da concorrência elaborado pelos economistas clássicos. De facto, ao admitir as sociedades anónimas - "verdadeiros "sindicatos de especulação"» na sua origem, como refere (p. 44), e um veículo jurídico talhado para o crescimento empresarial ilimitado - e ao sujeitar a sua constituição ao "sistema normativo" (ie, ao dispensar a sua constituição de uma aferição prévia "em termos político-econó- 
Tendo-a presente, as tantas vezes apregoadas virtualidades concorrenciais das marcas (e da tutela da lealdade da concorrência, e das alterações aos figurinos das sociedades, e etc.), volvem-se em algo diverso, se é que não mesmo no seu oposto: na defesa dessa desigualdade instituída - na protecção das posições alcançadas pelos já instalados no mercado ${ }^{33}$. O que implica uma outra consequência, e de não pouca monta: a de que por detrás do manto diáfano do Direito está a nudez crua dos interesses.

É claro que esta racionalidade imputada à história das instituições - ainda para mais revelando a mistificação da sua ostensiva fundamentação ${ }^{34}$ - e a identificação de um padrão comum nos

micos e económico-concorrenciais" - p. 49), o que os diversos legisladores nacionais fizeram foi criar as condições para que a concorrência se tornasse desigualitária, relativizando-a e desvalorizando-a perante a liberdade contratual (inclusive a de a limitar): cfr. pp. 50-52 e 352-356.

Num sentido próximo, defendendo que o direito antitrust está indevidamente fundado no modelo do ilícito (no "crime tort model"), quando devia estar fundado no direito societário (no "corporate regulatory model"), v. D. Crane, “Antitrust Antifederalism”, California Law Review, Vol. 96, n. ${ }^{\circ}$ 1, pp. 1-62 (February 2008).

${ }^{33}$ Passagens-chave: "a deslealização da concorrência não foi pensada para purificar a concorrência, igualizando os concorrentes na concorrência, mas sim para defender os elementos de monopólio $e$, por conseguinte, consolidar a desigualdade dos concorrentes." (pp. 884). Até porque, como escreve noutro passo (p. 881), "a desigualdade-na-concorrência, que é corolário da desigualização dos concorrentes, gera desigualdade-na-concorrência desleal, ou seja, a necessidade de alguns concorrentes serem mais desleais que outros".

Sirva também um exemplo retirado da exposição sobre a proibição da "venda com brindes" em França (p. 533): "a proibição de engano no reclame, não importando (...) como o engano se concretiza, embora aproveite a todos os empresários (e, por isso, pode dizer-se estatuída no seu interesse de categoria) - e aproveita-lhes porque se posterga uma forma insidiosa de alterar as posições adquiridas pelos vários concorrentes - não interessa a todos eles em igual medida: a ausência de uma qualquer disciplina na publicidade (dando-se guarida a um struggle for life) haveria necessariamente de ser mais gravosa para os empresários que, estando em vantagem, quer do ponto de vista económico-financeiro, quer técnico (direitos de propriedade industrial e know-how incluídos), quer ainda no que concerne às estratégias de marketing^ ocupam as posições mais apetecidas (posições-padrão) e, por isso mesmo, mais expostas a contestação, maxime, pelos "empresários marginais". ( Nota suprimida).

34 "continuando a falar-se de liberalismo para caracterizar esse novo (modo de ser do) capitalismo, que se queria "organizado", e que se foi afirmando na segunda 


\section{diferentes percursos evolutivos dos vários institutos enumerados, deixa outras questões em aberto $^{35}$, mas o propósito confessado do}

metade do século XIX (...) deu-se azo a outro tipo de mistificações. Entre elas avulta a de se (poder) ter continuado a apresentar o sistema capitalista como uma luta (constante) pela liberdade económica e, consequentemente, pela liberdade de concorrência, na medida em que se entende que aquele é pressuposto desta. Por via dessa equiparação (ideologicamente motivada) do capitalismo à liberdade de concorrência (...) todas as restrições que foram sendo impostas a essa liberdade (a tutela das marcas e a disciplina da concorrência desleal constituem apenas dois exemplos), e que se revelaram indispensáveis para a subsistência (organizada) do sistema, puderam ser apresentadas como meios de defesa e, mais do que isso, de luta por essa mesma liberdade de concorrência." - p. 699.

"Uma mistificação do mais alto coturno: tornada impossivel a liberdade de concorrência, à luz dos objectivos que passaram a ser os do sistema, sendo precisamente essa impossibilidade que fazia com que a concorrência pudesse ser desleal, foi possível continuar a dizer que, restringindo a liberdade de concorrência, o que afinal se visava era a defesa da própria liberdade de concorrência!" - p. 765.

"com o manuseamento da tutela da marca e com o recurso à disciplina da concorrência desleal, a jurisprudência francesa (...) chegou a um resultado em tudo similar àquele que era almejado pela disciplina das Corporações do Ancien Régime: a proscrição da concorrência de preço. Dizer que, no primeiro caso, estando em causa a tutela da marca e a proibição da concorrência desleal, era a liberdade de concorrência que era objecto de defesa, ao passo que, no segundo caso, por haver estatuições expressas sobre a proibição de certas formas de concorrência, era a defesa do monopólio que se contemplava, só pode ser levado à guisa de unia profunda mistificação." - p. 783.

"recorrendo à disciplina da concorrência desleal (...) [conseguiram-se] repetir no quadro de um sistema sócio-económico-político, que se dizia baseado na liberdade de comércio e indústria (ou, o que vale o mesmo, o princípio da liberdade de iniciativa económica), as soluções mais tipicamente corporativas do Ancien Régime, que sempre foram tidas, por isso mesmo, como profundamente anti-concorrenciais." - p. 789.

Mais adiante (pp. 1079-1080) acrescenta: "O adjectivo unfair (...) não deixava de funcionar como uma artimanha: permitia fazer passar a defesa dos monopólios como um ataque às maldades dos homens(-empresários); além disso, punindo os "desleais" - via de regra os concorrentes de menor dimensão, que luta(va)m pela sua sobrevivência no mercado - apresentando-os como os ímpios do sistema, este, para além de se dizer economicamente vantajoso, poder-se-ia apresentar como ético-socialmente eficiente."

${ }^{35}$ Uma das quais, relevando já de um Programa de Investigação Técnico, o A. formula assim: "dada a pluralidade de funções económicas da marca [O A. refere-se ao que designa por função de origem da marca (desdobrada em "função de origem nominada" e "função de origem anónima"), função de distinção, função de publicidade (ou função sugestiva) e função de garantia (também dita função de qualidade ou função de confiança)], será que todas elas podem ser abrangidas pelo direito que the é próprio, beneficiando da consequente tutela jurídica?" (pp. 1246-1248). Ou seja, 


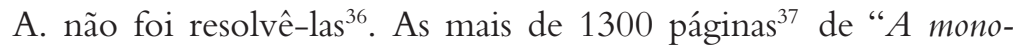
polização da concorrência e a tutela da marca" podem ser vistas como expressão do que Jagdish Bhagwati denominou "the Dracula Principle": "expose evil to sunlight to destroy it"38. Ou, citando

é a questão da adequação do "âmbito normativo" das marcas ao seu "âmbito ontológico" (cfr. a nota 2452 da obra em epígrafe, remetendo para A. VAnZETti).

A mais da identificação da raiz da evolução acima descrita (cfr. nota 31: que razões estruturais, ligadas sobretudo ao desenvolvimento económico, podem ser invocadas para explicar a ubíqua conspiração da protecção dos detentores de poder de mercado?), outra questão directamente decorrente da tese do A. (por ela suscitada) prende-se com a origem do - aparentemente necessário - "disfarce" de que se revestem as restrições à concorrência (nunca assumidas como tal), e com a função (decerto legitimadora) dessa mistificação. Para o que sugere um princípio de resposta: "a razão social está hoje inteiramente sufocada pela razão económica" e o "eficientismo" é um "filho dilecto" desse "pensamento único". p. 469. Sobre a transformação de uma "economia de mercado" numa "sociedade de mercado" "Instead of economy being embedded in social relations, social relations are embedded in the economic system.", v. K. PolanyI, The Great Transformation, Beacon Press, Boston, 1994 - a citação é da p. 57 -, e A Ilusão da Economia, Edições João Sá da Costa, Lisboa, 1999).

Admitindo também que o balanceamento de forças entre comércio e indústria é hoje diferente do que foi considerado no quadro temporal a que se cingiu o A. (cfr. a transcrição que fizemos na referida nota 31), também se podem questionar as alterações que os diferentes institutos gerados para reforçar o (e pelo reforçar do) predomínio de um sobre o outro, podem acomodar.

${ }^{36}$ Como escreveu A. Hirschman (As Paixões e os Interesses - Argumentos políticos a favor do capitalismo, antes do seu triunfo, Bizâncio, Lisboa, 1997, p. 158), "tudo o que podemos esperar da história e, em particular, da história das ideias" é "não que resolva os problemas, mas que contribua para melhorar o nível do debate."

${ }^{37}$ Das quais 53 de referências bibliográficas.

38 T. N. Srinivasan, "Discussion", em J. de Melo/A. Panagariya eds., New Dimensions in Regional Integration, Centre for Economic Policy Research/ Cambridge University Press, Cambridge, 1993, nota 1, p. 88. De facto, no local por ele citado (The World Trade System at Risk, Harvester/Wheatsheaf, New York, 1991, Appendix I - que cumpre a mesma função de "Clarifying Conceptual Confusions and Refuting Fallacies"), Bhagwati não usa a expressão. Mas foi ele que comentou "an earlier draft" da intervenção de Srinivasan e foi a ele que Srinivasan a atribuiu.

O mal - aqui como em outras latitudes - deve estar na muito entranhada crença na "indiferença da técnica": saber as soluções sem conhecer as suas causas é a primeira razão da sua (recorrente) racionalidade perversa - como a presente tese abundantemente demonstra. 
Louis Brandeis, outra referência do ofício ${ }^{39}$, como uma forma de levar à prática o princípio de que "A luz do sol é o melhor dos desinfectantes».

É esse caminho, agora bem iluminado, que outros podem percorrer.

\author{
Victor Calvete \\ Faculdade de Direito de Coimbra
}

${ }^{39}$ O hipotético leitor deve desconsiderar a "private joke" e ser informado de que cheguei à fórmula citada por via de S. D. Levitt/S. J. Dubner, Freakonomics - O Estranho Mundo da Economia - O lado escondido de todas as coisas, Ed. Presença, Lisboa, 2006, p. 83.

$\mathrm{Na}$ sua declaração de voto (de vencido) em Quaker City Cab Co. v. Pennsylvania, de 1928, Brandeis (Justice do Supreme Court entre 1916 e 1939) o paladino do "small business" e autor de uma recolha de escritos sob o título The Course of Bigness -, também oferece um adequado epílogo para esta recensão: "there are still intelligent, informed, just minded, and civilized persons who believe that the rapidly growing aggregation of capital through corporations constitutes an insidious menace to the liberty of the citizen; that it tends to increase the subjection of labor to capital; that, because of the guidance and control necessarily exercised by great corporations upon those engaged in business, individual initiative is being impaired and creative power will be lessened; that the absorption of capital by corporations, and their perpetual life, may bring evils similar to those which attended mortmain; that the evils incident to the accelerating absorption of business by corporations outweigh the benefits thereby secured; and that the process of absorption should be retarded." Mesmo que o "recensor" não partilhe a última conclusão - como R. SChragger, "The Anti-Chain Store Movement, Localist Ideology, and the Remnants of the Progressive Constitution, 1920-1940", Iowa Law Review, Vol. 90, 2005, n. 3 pp. 1011-1094, (de onde a transcrevemos - p. 1051) - subscreve sem reservas a primeira. 